\title{
TRAS SETENTA AÑOS DE VIGENCIA DE LA DECLARACIÓN UNIVERSAL DE DERECHOS HUMANOS
}

\section{¿PODRÍA CONSIDERARSE EL NUEVO DERECHO NATURAL DE LA HUMANIDAD?}

\author{
"La Declaración Universal de Derechos Humanos es \\ indudablemente la expresión de la conciencia jurídica \\ de la humanidad, representada en la ONU y, como tal, fuente \\ de un derecho superior de un higher law, cuyos principios \\ no pueden desconocer sus miembros." (R. CASSIN)
}

\begin{abstract}
RESUMEN. La presente reflexión plantea la posibilidad de rehabilitar la propuesta iusnaturalista, que tanto ha contribuido históricamente al desarrollo de los derechos humanos, aplicada al texto de la Declaración Universal de 1948.Se trataría, en cualquier caso, de una propuesta inscrita en el iusnaturalismo deontológico y crítico (no ontológico), donde el Derecho Natural se configura como ética jurídica y parámetro de valoración de la legitimidad de los ordenamientos positivos. En este sentido la Declaración Universal constituye todavía el primer y más significativo documento para la construcción de una ética universal y planetaria.
\end{abstract}

PALABRAS CLAVES. Declaración Universal. Derechos humanos. Dignidad de la persona. Iusnaturalismo deontológico. Consenso valorativo. Etica universal

ABSTRACT. The present reflection raises the possibility of rehabilitating the natural law proposal, which has historically contributed so much

* Profesora titular de Filosofía de Derecho de la Universidad Complutense de Madrid y miembro del Observatori de Bioética i Dret de la Universidad de Barcelona. Correo electrónico: mlmarincastan@gmail.com 
to the development of human rights, applied to the text of the Universal Declaration of 1948. In any case, it would be a proposal inscribed in deontological and critical natural law (not ontological), where Natural Law is configured as a legal ethic and a parameter for assessing the legitimacy of positive orders. In this sense, the Universal Declaration is still the first and most significant document for the construction of a universal and planetary ethics

KEY WORDS. Universal Declaration. Human rights. Dignity of the person. Deontological Iusnaturalism. Valorative consensus. Universal ethics.

\section{INTRODUCCIÓN}

Como es sabido, el próximo 10 de diciembre se conmemora el 70 aniversario de La Declaración Universal de los Derechos Humanos aprobada por Resolución de la Asamblea General de la ONU en 1948. Este texto ha constituido, sin duda, un avance sin precedentes en el largo camino hacia la civilización de la dignidad humana y el hito más importante del vasto proceso de internacionalización de los derechos humanos, concebidos todos ellos como concreciones de este valor o principio fundamentador, en cuya virtud ha sido posible una concepción común de los mismos. A partir de la Declaración se han elaborado y aprobado en el contexto de Naciones Unidas una serie considerable de instrumentos dirigidos a desarrollar y dotar de eficacia las disposiciones de la Declaración, que han venido a materializar una concepción común de la dignidad propia del mundo contemporáneo.

Es innegable que la Declaración Universal ha puesto los cimientos para un mundo más justo y que, desde luego, se ha avanzado mucho en la protección de los derechos humanos desde 1948, aunque todavía quede mucho por hacer. Este significativo texto, que es el primero de carácter jurídico-internacional que formula un catálogo omnicomprensivo de derechos humanos con pretensión de validez universal es el punto de partida del combate moderno para la protección de tales derechos ${ }^{1}$.Estos aparecen enunciados en sus treinta artículos, donde se explícita el sistema de valores fundamentales universales que concretan y desarrollan las ideas de dignidad humana, libertad, igualdad y justicia.

Se puede afirmar, en consecuencia, que a partir de la Declaración se produce un cambio de paradigma en la concepción del Derecho internacional contemporáneo. A diferencia del Derecho internacional clásico, que era de carácter estado céntrico, concebido como un derecho entre Estados, se consagra hoy el reconocimiento del interés humano en el orden de los valores y, consecuentemente, la obligación de los Estados de hacer de dicho interés -concretado en la idea de dignidad y derechos fundamentales- uno de los principios constitucionales del nuevo orden internacional. Así, el hombre, la persona humana o la humanidad en su conjunto aparecen actualmente como sujetos de Derecho internacional. ${ }^{2}$.

\footnotetext{
${ }^{1}$ Sommermann,K.P. "El desarrollo de los derechos humanos desde la Declaración Universal de 1948, en Derechos humanos y constitucionalismo ante el tercer milenio, coord. A.E, Pérez Luño, Marcial Pons, Madrid, 1996, p. 98.

${ }^{2}$ Carrillo Salcedo, J.A. Dignidad frente a barbarie. La Declaración Universal de Derechos Humanos cincuenta años después, Trotta, Madrid, 1999, pp. 16 y 17.
} 
La Declaración es la piedra angular del sistema de Derecho internacional de los derechos humanos.

Como sostienen prestigiosos especialistas en la materia, la internacionalización de los derechos humanos, lejos de obedecer a una evolución natural, constituye una auténtica ruptura pues supone una etapa que no es prolongación natural de las anteriores. ${ }^{3}$ Con sumo acierto, René Cassin, uno de los padres de la Declaración, consideraría esta como el primer documento ético que haya jamás adoptado la humanidad organizada.

Las siguientes páginas tienen por objeto suministrar algunas reflexiones realizadas en el ámbito de la filosofía del derecho y la filosofía moral sobre la pertinencia -habida cuenta del consenso sobre los valores y principios que implica la Declaración Universal para evaluar la legitimidad de los derechos positivos - de considerar ésta como el nuevo Derecho Natural de la Humanidad. Lógicamente, no nos estamos refiriendo con ello a un iusnaturalismo tradicional, radical o dogmático, sino a un iusnaturalismo abierto, flexible y crítico, más compatible con la forma de entender el consenso sobre los valores en la actualidad, que sostiene la existencia de principios morales y de justicia universalmente válidos para inspirar y orientar necesariamente los derechos positivos.

La pauta de reflexión que sugiero se concreta, pues, en la idea de una posible rehabilitación y recuperación de la propuesta iusnaturalista que tanto contribuyó en otras etapas de la Historia a la reivindicación de los derechos humanos universales, concebidos bajo el prisma de los derechos naturales Se trata, por tanto, de rescatar, mediante la propuesta que formulamos, lo que consideramos todavía como el núcleo valido y rescatable de esta tradición que tanto juego ha dado a lo largo de la de la cultura jurídica y que, como sabemos, constituye una constante recurrente en el pensamiento jurídico occidental. Para ello partimos de algunas significativas contribuciones a la filosofía del derecho y a la filosofía moral que nos van a ayudar a fijar el significado, el contenido y los términos en los que se articularía y concretaría la adopción de la perspectiva epistemológica del iusnaturalismo, aplicada al análisis de las formulaciones contenidas en el texto de la Declaración Universal de Derechos Humanos.

\section{DEL DERECHO NATURAL ONTOLÓGICO AL DERECHO NATURAL DEONTOLÓGICO}

En una primera aproximación, suele entenderse por iusnaturalismo una multiplicidad de teorías y corrientes doctrinales, ciertamente muy diversas, pero con un denominador común: la creencia en un orden superior o supra positivo, de carácter universal, permanente e inviolable en el que se contienen los principios últimos del obrar humano y que resultan racionalmente cognoscibles. El iusnaturalismo defiende, por tanto, la superioridad del Derecho natural sobre el Derecho positivo.

Sin embargo, pese a las múltiples versiones de la doctrina del Derecho Natural, que no se deben presentar como un bloque unitario, se pueden diferenciar dos niveles distintos de análisis, según se aluda al Derecho natural concebido como ontología o al Derecho natural como deontología. En la primera fórmula el derecho natural aparece como el" ser" del derecho; en la segunda como sistema universal e inmutable de valores, como "deber ser" del derecho positivo, como la pretensión del derecho positivo que pretende ser justo. 
Así pues se puede decir -siguiendo a Elías Díaz- que la primera concepción, el derecho natural ontológico, que es la más tradicional en el iusnaturalismo escolástico- medieval, resulta englobante de la segunda (Derecho natural deontológico): el "ser" (natural) del derecho se constituye como" deber ser" del derecho positivo. Por el contrario, no ocurre lo mismo en sentido inverso: la segunda concepción no es englobante de la primera; esto quiere decir que cabe admitir la existencia de valores universales e inmutables sin considerar que esto sea propia y auténticamente derecho, sino más bien ética. Esta última postura, heredera del iusnaturalismo racionalista moderno a partir de la separación efectuada entre derecho y moral, difiere, por consiguiente, de la primera (del Derecho natural trascendente ontológico), dónde además de aparecer el Derecho natural como sistema inmutable, necesario y universal de valores, es este, únicamente, el verdadero y auténtico derecho y el derecho positivo solo lo es si concuerda exactamente con aquel. ${ }^{4}$

En efecto, la concepción del Derecho Natural ontológico, que es la más tradicional y a la que también se califica de "dogmática "o "metafísica, "sostiene una concepción objetiva y absoluta de la justicia. Esta aparece arraigada en el ser del Derecho y, en consecuencia, el mismo se concibe como un sistema completo que puede solucionar todos los problemas que surjan en la realidad jurídica. El Derecho Natural es aquí auténtico derecho. Mientras esta concepción, pese a ser la más pura y genuina del iusnaturalismo y contar todavía con algunos autorizados exponentes, resulta minoritaria en nuestros días ${ }^{5}$, no ocurre lo mismo con la concepción deontológica, que ocupa un lugar importante en el pensamiento jurídico contemporáneo, aunque a su vez diste mucho de ofrecer un contenido doctrinal homogéneo y sea susceptible de muchas y variadas versiones.

En un somero recorrido a lo largo del pasado siglo, podemos referirnos, en el ámbito de la cultura jurídica alemana, al famoso "Derecho natural de contenido variable" que ya formulara en su día R.Stammler (1856 - 1938), pasando por la doctrina de la naturaleza de la cosa de G. Radbruch (1878-1949) o W. Maihofer(1918-2009). También debe incluirse aquí el iusnaturalismo de base existencialista, de R. Marcic (1919-1971), el de la inspiración fenomenológica de Maihofer o H. Coing (1912-2000), quién atribuye a la idea de Derecho un contenido ético del que deduce normas que se encuentran condicionadas por el modo en el que en un determinado periodo histórico los miembros de una determinada sociedad interpretan los valores. Se debe añadir el de Welzel, con su teoría de las estructuras lógicoónticas, expresada en su Introducción a la filosofía del derecho, Derecho Natural y justicia material (1951) ${ }^{6}$, hasta planteamientos más recientes, como los de K. Larenz Derechojusto. Fundamentos de ética jurídica (1978) o A. Kaufman con su idea de "búsqueda en un derecho natural histórico -concreto 7 . E incluso también podría tener cabida en este rótulo la

3 Imbert, P. H. "Los derechos humanos en la actualidad", en Derechos humanos y constitucionalismo...op. cit. p.73.

${ }^{4}$ E., Sociología y filosofía del derecho, Taurus, Madrid, 1977 págs. 279 y 280.; Vid. Fernández, E: “El iusnaturalismo", en El derecho y la justicia eds. E. Garzón Valdés y F. Laporta, Trotta- C.S.I.C. B.O.E.:, Madrid, 1996, págs.. 55 a 64.

${ }^{5}$ Vid. un panorama de estas orientaciones en Hernández Gil A. De nuevo y sobre el Derecho Natural, Real Academia de Jurisprudencia y Legislación, Madrid, 1983. En relación a nuestro país, específicamente, puede consultarse AAV El Derecho Natural hispánico, Escélicer, Madrid, 1973.

${ }^{6}$ Introducción a la filosofía del derecho. Derecho natural y Justicia material, Trad F: González Vicén, Aguilar, Madrid, 1971.

7 Kaufman, A. y Hassemer W. (eds.). El pensamiento jurídico contemporáneo, ed.española de G, Robles, Debate, Madrid 1992. Una exposición de las principales doctrinas iusnaturalistas contemporáneas 
propuesta crítico-marxista y utópica de E Bloch expresada en su obra Derecho Natural y dignidadhumana.

Desde otra perspectiva y en un contexto intelectual diferente, el del pensamiento angloamericano con la renovación de los planteamientos en la filosofía moral, jurídica y política como reacción al utilitarismo y la actitud crítica frente a algunos planteamientos de la filosofía analítica llevada a cabo en la década de los 70, también contamos con importantes contribuciones muy próximas a estos planteamientos- siempre y cuando adoptemos una perspectiva iusnaturalista inclusiva - que incorporan aspectos nuevos e interesantes que conviene tener en cuenta. De este modo, no sin algunas reservas y matices, podemos incluir desde una acepción sumamente abierta de la expresión "iusnaturalismo" las concepciones de R. Dworkin ${ }^{8}$ o J. Rawls, quien en su propuesta del Derecho de Gentes alude a "lo que las leyes de todos los pueblos tienen en común, una concepción política de la equidad y la justicia que se aplica a los principios y a las normas del Derecho Internacional y a su práctica "9 Si bien es cierto que la mayor parte de las veces no hay en ellas invocación expresa alguna al término" Derecho natural", sino que, por el contrario gran parte de sus exponentes - tratando de superar el círculo vicioso de la antítesis iusnaturalismopositivismo -se refieren a los "derechos morales".

Como señala Pérez Luño se utiliza aquí el término iusnaturalismo en su acepción deontológica funcional y abierta, teniendo cabida dentro de este rótulo posiciones tales como las que se han venido a caracterizar de iusnaturalismo atípico o iusnaturalismo relativo frente al iusnaturalismo absoluto, iusnaturalismo en sentido débil, frente al iusnaturalismo ontológico que sería iusnaturalismo en sentido fuerte o iusnaturalismo dogmático, que resultaría muy poco compatible con las sociedades multiculturales, plurales y diversas propias del tiempo que nos ha tocado vivir ${ }^{10}$.

Las posiciones reseñadas, en relación con el tema de los derechos humanos, constituyen, por tanto, un tipo de teorías de la justicia que sostienen la existencia de una serie de principios y exigencias morales, que en un momento histórico determinado se consideran universales e intangibles. Consecuentemente con ello, propugnan la necesidad insoslayable de que todo orden jurídico reconozca los derechos básicos de quiénes lo integran y que son previos a las instituciones jurídico políticas (pre institucionales) por su especial relevancia; toda vez que responden, precisamente, a exigencias éticas, bienes, valores y principios morales que afectan a todos los seres humanos por el mero hecho de serlo, así como también dichas teorías defienden la posibilidad de conocer y justificar racionalmente tales aspiraciones, valores o necesidades que demandan una pretensión de ser incorporados a los sistemas jurídicos positivos si no lo estuvieran todavía. ${ }^{11}$

en Alemania, puede verse en Ellscheid, G., "El problema del Derecho Natural. Una orientación sistemática", ibidem, pp. 145 y ss.

${ }^{8}$ Dworkin, R., Los derechos en serio Ariel, Barcelona, 1984.

9 Rawls, J. El Derecho de Gentes y una revisión crítica de la idea de razón pública, Paidós, Barcelona,2001, p.14.

${ }^{10}$ Perez Luño, A. E. Derechos humanos, Estado de Derecho y Constitución, Tecnos, Madrid, 1984, p. 137.

${ }^{11}$ Vid. Sobre el tema Añón, M.J. "Los Derechos Humanos como derechos morales: aproximación a unas teorías con problemas de concepto, fundamento y validez “,en Ballesteros, J. (ed). Derechos Humanos, Tecnos, Madrid, 1992, pág. 61 y ss. 
Teniendo en cuenta lo anterior el marco de reflexión en el que se sitúa el problema que nos ocupa es el de este conjunto de teorías ciertamente heterogéneas, plurales y variadas, que coinciden en afirmar la existencia de una serie de principios y exigencias morales universales e inviolables derivadas de una cierta idea de dignidad humana y que tiene que asumir y garantizará todo orden jurídico positivo para merecer la condición de Derecho justo o al menos el más justo posible en determinar la coyuntura espacio-temporal. Estos principios constituyen, pues, el modelo de moralidad de los derechos positivos.

Como en su momento ya escribiera Welzel: "lo que queda del mundo de ideas el derecho natural no es un sistema de principios jurídicos materiales eternos, sino la exigencia frente al derecho positivo- una exigencia que hay que cumplir bajo condiciones siempre nuevasde la que la lucha en torno a la confirmación justa de las relaciones sociales sea siempre una polémica entre ideas y no se trate de poner fin a ella por el sometimiento, ni mucho menos por la aniquilación del hombre por el hombre."12

\section{EL CONSENSO SOBRE LOS VALORES}

Sostenía ya hace más de dos décadas N.Bobbio que hay tres modos de fundar los valores: $1^{\circ}$ ) deducirlos de un dato objetivo y constante, por ejemplo, la naturaleza humana; $2^{\circ}$ ) considerarlos como como verdades evidentes por sí mismas; $3^{\circ}$ ) descubrir que en un determinado período histórico son generalmente consensuados(la prueba, precisamente, del consenso). Desde su posición de positivista crítico, el autor citado deja claro que, aunque el primer modo ofrecería la mayor garantía de su validez universal requeriría admitir como hipótesis previa la idea de si realmente existe la naturaleza humana como dato constante e inmodificable, así como el que pudiéramos conocerla en su esencia, ante lo que objeta que, "la historia del iusnaturalismo nos demuestra que la naturaleza humana ha sido interpretada de los modos más diversos y que la apelación a la misma ha servido para justificar sistemas de valores e incluso opuestos entre sí." El segundo modo -la apelación a la evidencia- tiene el defecto de presentarse más allá de toda prueba y rechazar cualquier otra posible argumentación de carácter racional. Sin embargo, el tercer modo de justificar los valores es mostrar que están apoyados en el consenso, según el cual un valor estaría tanto más fundado cuanto más compartido fuese.

Así pues, con el argumento del consenso se sustituye la prueba de la objetividad considerada esta última por Bobbio imposible o extremadamente incierta -por la de la intersubjetividad. Se trata ciertamente de un fundamento histórico y, como tal, no absoluto; pero lo histórico del consenso es el único fundamento que puede ser probado factualmente. En tal orden de cosas debe aceptarse la Declaración Universal de Derechos Humanos, "como la mayor prueba histórica que nunca haya existido del consensus omnium gentium acerca de un determinado sistema de valores .... No sé si nos damos cuenta de hasta qué punto la Declaración Universal representa un hecho nuevo en la historia, en cuanto que por primera vez .... un sistema de principios fundamentales de la conducta humana ha sido libre y expresamente aceptado, a través de sus gobiernos respectivos, por la mayor parte de los hombres que habitan la tierra. Con esta Declaración un sistema de valores es (por primera vez en la historia) "universal" " no en principio, sino "de hecho", en cuanto que el consenso

\footnotetext{
${ }^{12}$ Introducción a la Filosofía del Derecho...op. cit. p. 267.
} 
sobre su validez e idoneidad para regir la suerte de la comunidad futura de todos los hombres, ha sido explícitamente declarado". ${ }^{13}$

Conforme a ello, según dicho autor, "la Declaración Universal de Derechos Humanos representa la manifestación de la única prueba por la que un sistema de valores puede ser considerado humanamente fundado y por tanto reconocido: esta prueba es el consenso general acerca de su validez. Los iusnaturalistas habrían hablado de consensus omnium gentium o humani generis" 14 .

Las palabras citadas -independientemente de cualquier consideración polémica acerca de la virtualidad del consenso en la fundamentación de los valores o en torno a la naturaleza de tal consenso (política histórica y no precisamente ética ) y que ha sido puesta de relieve recientemente por excelentes cultivadores de la Filosofía del Derecho española ${ }^{15}$-entrañan una enjundia digna de comentario. En efecto, por primera vez en la historia de la cultura jurídica nos encontramos con un denominador axiológico común que se produce por el acuerdo expreso sobre las ideas de dignidad libertad e igualdad humanas, como eje en torno al cual gira el articulado del documento que analizamos- y que se plasma en un texto escrito, la Declaración Universal de las Naciones Unidas- que consagra unos derechos humanos básicos sustentados sobre tales valores a los que ha de dotar de concreción y realización.

Con la Declaración ha sido, pues, posible llegar a este consenso, que lejos de traducirse en fórmulas abstractas y vacías se concreta en sus treinta artículos y recibe su soporte material del conjunto de necesidades básicas de los seres humanos. Únicamente a partir de la aprobación de dicho documento se ha tenido la constancia histórica de que toda la humanidad comparte determinados valores y principios que han sido explícitamente declarados, previo el logro del acuerdo desde muy diferentes concepciones del mundo, de la vida, del hombre y de la sociedad.

Como escribe Rabossi, la Declaración Universal" supone con carácter esencial un diálogo y una discusión racionales, regidos por reglas procedimentales explícitas y dirigidas a obtener un acuerdo generalizado respecto de lo que en la propia Declaración se denomina el ideal común de la Humanidad. Supone así un salto cualitativo de primera magnitud en la historia de la humanidad, toda vez que se caracteriza por ser una empresa de carácter universal basada en un consenso, también universal, logrado y positivizado acerca de un

${ }^{13}$ Bobbio, N."Presente y porvenir de los Derechos Humanos" en El tiempo de los derechos, Sistema, Madrid, 1990, pp. 66 y 67.

${ }^{14}$ Ibidem, p. 64.

${ }^{15}$ Vid. Muguerza y otros, El fundamento de los derechos humanos.,Debate, Madrid, 1989; De Lucas, J." De algunos equívocos sobre el concepto y fundamentación de los derechos humanos", en Ballesteros J. Derechos humanos...., op. cit. p 13 y ss. ; Ollero Tassara, A. Derechos humanos y Metodología Jurídica C. E. C., Madrid 1989 pp. 149 y ss; Robles Morchón, G, Los derechos fundamentales y la ética en la sociedad actual, Cívitas, Madrid, 1992;Lucas Verdú, P. Los derechos humanos como religión civil. “.Derechos humanos y concepción del mundo y de la vida. Sus desafíos pendientes”, en Consolidación de derechos y garantías :los grandes retos de los derechos humanos en el siglo XXI,CGPJ,,Madrid,1999,, pp 225 y ss. Puy Muñoz, F." ¿Qué tiene que fundamentar una fundamentación teórica de los derechos?”, en Derechos Humanos:Problemas actuales. Estudios en homenaje al Profesor Benito de Castro, UNED,,Madrid, 2013,Vol I, pp.141 y ss;;Martínez García, J.I. "Reconocimiento constitutivo de los derechos humanos, ibidem, pp.75 y ss.;Barranco Avilés, M. C. "Las teorías de los derechos humanos en el siglo XXI", en EL tiempo de los derechos. Los derechos humanos en el siglo XXI, M. Revenga y P. Cuenca (eds), Dykinson, Madrid, 2015, pp. 13 y ss. 
plexo valorativo y de principios básicos que tiene como núcleo principal las ideas de dignidad, de igualdad, de libertad y de justicia ". ${ }^{16}$

La compatibilidad entre la fórmula del consenso en la determinación de los valores y los planteamientos de este iusnaturalismo "latu sensu" o iusnaturalismo abierto, inclusivo y flexible ha quedado sobradamente probada, como lo demuestran por ejemplo, las teorías de Rawls o Dworkin, que expresan orientaciones procedimentales sobre la fijación del significado y alcance de los valores y principios constitucionales desde premisas -como ya se ha dicho- muy próximas a las posiciones iusnaturalistas.

Entre nosotros, han recogido estas orientaciones, entre otros, Delgado Pinto y Pérez Luño, cuando ambos propugnan la actualización de la tesis iusnaturalista de la competencia de la razón práctica para fundar los valores éticos jurídicos. Así, el primer autor señala al respecto que "revisten mayor interés los intentos de delinear las condiciones de una situación hipotética de discusión racional que, asumida idealmente, nos permitiría enunciar no solo fórmulas vacías, sino verdaderos principios materiales de Justicia universalmente validos; es decir. que habrían de ser tenidos en cuenta para la ordenación justa de cualquier sociedad"17.A su vez, Perez Luño estima que puede resultar muy provechoso abordar la interpretación de los derechos humanos a partir de las premisas del iusnaturalismo crítico," que sitúa la justificación de los valores y derechos básicos en una actitud inter subjetivista, es decir, en el reconocimiento de la posibilidad de que la razón práctica llegue a un consenso abierto y revisable sobre el fundamento de tales derechos y valores" 18 .

Es pues en estos términos de consenso abierto histórico y revisable sobre los valores y los derechos humanos que los concretan y realizan donde ciframos el valor y alcance de los enunciados de la Declaración Universal de1948. Y desde esta perspectiva podemos considerar que este posible Derecho Natural que se plasma en ella se configura, como muy acertadamente señala Truyol-siguiendo a R. Cassin - a modo de higher law, como "derecho superior" informado por valores comunes compartidos por todos los hombres y que van más allá del ámbito propio de los Estados. Afirmaba en este sentido R. Cassin con las palabras que encabezan este texto, que la Declaración "es indudablemente la expresión de la conciencia jurídica de la humanididad, representada en la ONU y, como tal, fuente de un derecho superior de un higher law, cuyos principios no pueden desconocer sus miembros" ${ }^{\prime 19}$.

${ }^{16}$ Rabossi, "El fenómeno de los derechos humanos, en Revista del Centro de Estudios Constitucionales, $\mathrm{n}^{\circ} 3$ (1989), p. 333 .

17 Delgado Pinto, J. De nuevo sobre el problema del derecho natural, Universidad de Salamanca, Salamanca 1982, p. 33.

${ }^{18}$ Perez Luño. A.. E., "La interpretación de los derechos fundamentales"”, en AA.VV., Pensamiento jurídico y sociedad internacional.( Estudios en honor del profesor Truyol Serra) CEC-UCM, Madrid, 1986, vol. II p. 983.

${ }^{19}$ Cassin, R. "La Déclaration Universelle et la mise en ouvre des Droits de l"Homme", en Recueil des Cours, $\mathrm{n}^{\circ} 79$, 1951, II, pp.239 y ss. 


\section{ACERCA DEL IUSNATURALISMO DIFUSO EN LA DECLARACIÓN UNIVERSAL}

En tal orden de consideraciones, la Declaración Universal vendría a concretar el contenido, aunque sea mínimo de la idea de justicia, de la moralidad del derecho, constituyéndose de tal suerte como una auténtica ética o justicia material y cumpliría en la sociedad actual- como se ha puesto de relieve por parte de algún especialista en la materia no precisamente filoiusnaturalista- la función reguladora que realizaban la cultura clásica el derecho natural ${ }^{20}$.

El proceso de supranacionalización y universalización de los derechos humanos que se inicia con la Declaración, ha permitido hablar a los especialistas de renacimiento de un "iusnaturalismo difuso", que surge auspiciado por los horrores de la Segunda Guerra Mundial, cuando los Estados toman conciencia de que el problema de la protección de los derechos humanos rebasa las fronteras nacionales para adquirir una dimensión netamente supranacional. Como señala B. de Castro "éste es en consecuencia el momento en que las declaraciones de derechos, no pudiendo legitimarse ya por referencia al sistema de valores predominante en un país exigen una plataforma valorativa que resulta aceptable para una serie de pueblos y regímenes políticos estructurados en torno a principios filosóficos políticos religiosos económicos y culturales bastante dispares"21.

Se puede afirmar, por tanto, sin temor a error, que a partir de la Declaración existen una serie de valores compartidos, una serie de principios jurídicos materiales, de ética jurídica, con cierta permanencia histórico-cultural, que han podido llegar a ser universalizados en el momento en que se aprobó el texto que comentamos. En palabras de I. Berlín, se trata de "un mínimo sin el que las sociedades difícilmente podrían sobrevivir con cierta objetividad y universalidad"22. Dichos valores, principios y normas, ahora contenidos en la Declaración, constituyen los supuestos de validez ético-jurídica -axiológicos y antropológicos- de todo sistema de derecho, en cuanto resultan absolutamente necesarios para la plena realización de la persona humana, tanto en su dimensión física como espiritual, así como también se configuran como presupuestos políticos, en cuanto son imprescindibles para garantizar la convivencia pacífica dentro de toda estructura política con pretensión de legitimidad.

Desde una perspectiva distinta de la propiamente iusfilosófica y con una orientación marcadamente internacionalista y garantista, A. CASSESE, prestigioso especialista en derechos humanos, aún sin utilizar -dado su planteamiento- un discurso argumentativo "ad hoc "sobre la fundamentación filosófica de la Declaración Universal, escribiría a tal efecto, que desde 1948 en que se proclamó la misma, "todos los países del mundo disponen de un código internacional para decidir cómo comportarse y como juzgar a los demás. Es un código que no solo actúa a nivel universal, sino que incluye preceptos que tienen valor en áreas anteriormente no tenidas en cuenta en las Constituciones de los Estados occidentales

${ }^{20}$ Peces-Barba, G., Curso de Derechos Fundamentales,( cols). R. de Asís y A. Llamas, Eudema, Madrid, 1991, Vol I p. 13.

${ }^{21}$ Castro Cid, B., "El reconocimiento de los derechos humanos, en la AA VV. Los derechos humanos. Significación. Estatuto jurídico y sistema, Universidad de Sevilla, Sevilla, 1979, pp. 27 y 28.

${ }^{22}$ Berlin, I." El fuste torcido de la humanidad." Capítulos de Historia de las ideas, (ed). H. Hardy., Península, Barcelona, 1992, p. 9. 
Ahora disponemos de parámetros de acción para los Estados y para los individuos: los preceptos internacionales acerca de los derechos humanos imponen una línea de conducta, exigen a los gobiernos que hablen de cierta forma y, al mismo tiempo, legitiman a los individuos para que lleven bien alto su voz si aquellos derechos y libertades no son respetados". Y en otro lugar de la misma obra señalaba, refiriéndose al significado de los derechos humanos, que "éstos sin duda, constituyen ya un nuevo Derecho Natural de la Humanidad.:no en el sentido del Derecho Natural tan escarnecido y aborrecido por los juristas, es decir, no en el sentido de un conjunto de preceptos hallados por individuos particulares (y por tanto arbitrariamente) en la razón humana y erigidos en cánones de conducta superiores al derecho positivo. Más bien en el sentido de un conjunto de parámetros de conducta y de evaluación concordantemente destilados- por obra de todos los Estados- de tradiciones ideológicas y filosóficas, de preceptos religiosos y concepciones del mundo, y transformados por los Estados mismos en Código Internacional de Conducta" ${ }^{23}$.

De todo lo anterior, resulta evidente que los enunciados de la Declaración Universal responderían plenamente -en cuento que materializan el consenso general sobre los valores y derechos humanos que los concretan- al modelo de lo que Perez Luño denomina "fundamentación intersubjetivista", que se presenta como alternativa tanto a los postulados ideológicos del objetivismo -en cuanto comporta fundamentar los derechos y valores en unos pretendidos postulados objetivos y apriorísticos- como a los del subjetivismo, y que entraña de tal suerte: frente al objetivismo, una revalorización del papel del sujeto humano en el proceso de identificación y justificación racional de los valores éticos jurídicos. Y frente al subjetivismo- que se traduciría en un puro decisionismo -la postulación de la posibilidad de "una objetividad intersubjetiva" de dichos valores, basada en la comunicación de los datos antropológicos que le sirven de base. El núcleo básico de esta concepción intersubjetivista reside en la idea de que los derechos se basan en necesidades humanas que emergen de la experiencia concreta de la vida práctica y que dichas necesidades, en cuanto datos social e históricamente vinculados a la experiencia humana, poseen una objetividad y universalidad que posibilitan tanto su generalización a través de la discusión racional y el consenso como su concreción en valores que pueden materializarse ${ }^{24}$.

En este planteamiento resulta claro que derechos humanos no se conceden, sino que se reconocen-son pre políticos y pre jurídicos-y se deben reconocer, precisamente porque existe un fundamento natural necesario e incontrovertible para ello, que es el mundo moral del hombre y la competencia de la razón práctica para detectar y explicitar estos principios y valores. Por tal motivo, la Declaración Universal tiene un alcance declarativo y no propiamente constitutivo: los derechos existen previamente y la Declaración los identifica y los consagra, por cuanto plasma la materialización del consenso sobre los mismos

\section{LA FUNDAMENTACIÓN DE LOS DERECHOS HUMANOS COMO DERECHOS MORALES}

El planteamiento anterior no difiere sustancialmente de la configuración de los derechos humanos como derechos morales. La locución moral rights proviene de la filosofía

\footnotetext{
${ }^{23}$ Cassese, A., Los derechos humanos en el mundo contemporáneo, Ariel, Barcelona, 1991, pp. 225 y 227

${ }^{24}$ Pérez Luño A. E. Derechos humanos, Estado de Derecho... op. cit., pp. 162 y ss.
} 
jurídica, política y moral angloamericana y ha logrado mucha aceptación entre los autores de habla hispana. A tal respecto debe destacarse la aportación de S. Nino en su emblemática obra Ética y Derechos Humanos, quien señala que "los derechos humanos son derechos establecidos por principios morales", afirmando que" la cuestión del reconocimiento de los derechos humanos es de tal importancia que difícilmente esté justificada una norma jurídica -y las decisiones judiciales y administrativas basadas en ellas-que negara o reteceará ese reconocimiento, por más que su origen fuera legítimo"25.

En esta concepción los derechos humanos se consideran como pre institucionales,, en el sentido de que existen y su respeto es exigible desde el ángulo de la moral, aunque ni los Estados ni la comunidad internacional los reconozca como derechos legales. Por consiguiente, los derechos morales, al residir en la moralidad básica, no resultan dependientes de las normas de derecho positivo y la juridificación de los mismos no es una característica constitutiva de estos, puesto que no resulta relevante para que exista un derecho moral. Estas teorías ponen el énfasis en su carácter universal e inalienable ${ }^{26}$, en el sentido de que su objeto nunca ha de ser modificado obligatoriamente (aunque pueda ser sacrificado de modo altruista) y en que dichos derechos protegen un bien que los individuos exigen para funcionar como agentes morales.

En España se han presentado como defensores y partidarios de esta tesis de los derechos morales, aún con diferentes enfoques y matices relativos a su asimilación o identificación con la noción de derechos humanos, autores, entre otros muchos, como E. Fernández, A. Ruiz Miguel o F..Laporta. Desde la perspectiva en la que tales autores se sitúan es posible la compatibilidad de los conceptos "derechos "y "morales", sin incurrir en la fusión e identificación de Derecho y $\mathrm{Moral}^{27}$.

La mejor fundamentación de estos derechos morales bien puede ser la aportada por los individuos y grupos, convencidos de su significado moral, que actúan como agentes morales en virtud de argumentos que saben sustentar con las mejores razones y que en la confrontación generalizada y en el debate público nacional e internacional aspiran al logro de un consenso que favorezca y promueva el respeto a la dignidad humana con una visión e interpretación de dicha idea que resulte "tendencialmente" universal. De tal modo que, -como muy acertadamente sintetiza M.J.Añón - las claves de las fuentes de legitimidad de los derechos morales, a pesar de los parciales desacuerdos entre sus teóricos, se pueden resumir en las ideas siguientes: $1^{\circ}$ ) dichos derechos deben ser consistentes con valores morales y sólidos; $2^{\circ}$ ) tales valores tienen un carácter preinstitucional o presocial, en el sentido de que funcionan independientemente de cualquier sistema de derecho positivo; $3^{\circ}$ ) los derechos provienen de las ideas morales de justicia y rectitud, por lo que la noción de Derechos Humanos debería sustentarse en una cierta teoría de los derechos sustantiva ${ }^{28}$.

${ }_{25}^{5}$ Nino, C.S: Ética y Derechos Humanos. Un ensayo de fundamentación, Ariel, Barcelona, 1989, pp. 19 y 24.

${ }^{26} \mathrm{Vid}$. Al respecto la interesante obra de Meyers, D. T. Los derechos inalienables, Alianza universidad, Madrid, 1988 , pp. 55 a 57.

${ }^{27}$ Un panorama de estas teorías en España se expone en en Barranco Avilés, M.C. El discurso de los derechos. Del problema terminológico al debate conceptual. Instituto de Derechos Humanos Bartolomé de las Casas, Universidad Carlos III, Dykinson, Madrid, 1996, pp 55y ss

28 Añón, M. J. "Los derechos humanos como derechos morales"... En J.Ballesteros (ed). Derechos Humanos .. op cit, pp 81 y 82 . 
Precisamente, un autor como J. Rawls, a quien se puede considerar inscrito en estas corrientes, expresa orientaciones muy próximas a esta idea de "derecho superior" o higher law a la que hemos aludido En su opinión, "los Derechos Humanos son una categoría especial de derechos diseñada para jugar un papel esencial en un razonable derecho de gentes para la época presente... constituyen una categoría especial de derechos de aplicación universal, difícilmente controvertibles en su intención general. Son parte de un razonable derecho de gentes y fijan límites a las instituciones domésticas exigidas por ese derecho a todos los pueblos. En este sentido, establecen la última frontera del derecho doméstico admisible en sociedades integrantes de buena fe, de una justa sociedad de los pueblos". ${ }^{29}$

El ámbito espacial de aplicación de la Declaración de Derechos Humanos -como indica su propio título- se extiende al mundo entero, no solo los miembros de la ONU, sino también a todos los Estados de la comunidad mundial; y es "universal" y no propiamente Internacional- como inicialmente se propuso- en la medida que constituye un esfuerzo, si bien tenue e impreciso, de afianzar el papel del individuo en el marco de un espacio antiguamente reservado a los Estados. Además, se habla de" Derechos Humanos"- cuya titularidad o ámbito de vigencia personal corresponde a todos los hombres-y no de meras exigencias o aspiraciones morales, lo cual supone que a estas pretensiones morales, que son previas a los ordenamientos positivos, se les reviste con evidentes signos jurídicos por su vocación clara de convertirse en derecho positivo. El propio "Preámbulo" de la Declaración -, a pesar de la proverbial controversia acerca de su naturaleza jurídica - alude claramente a la necesidad de su articulación en normas jurídicas, por cuanto en él se señala que," es esencial que los Derechos Humanos sean protegidos por un régimen de Derecho, a fin de que el hombre no se vea compelido al supremo recurso de la rebelión contra la tiranía y la opresión".

Esta misma idea aparece reafirmada en el artículo 29 , apartado $2^{\circ}$, cuando se determina que: "En el ejercicio de sus derechos y en el disfrute de sus libertades, toda persona estará solamente sujeta a las limitaciones establecidas por la ley con el único fin de asegurar el reconocimiento y el respeto de los derechos y libertades de los demás, y de satisfacer las justas exigencias de la moral, del orden público y de bienestar general en una sociedad democrática”. Es decir, la sociedad democrática se erige como limité a las excepciones o limitaciones de los derechos y libertades que puedan establecerse por la ley; incluso cuando esta ley pretenda justificarse en exigencias de la moral, del orden público o del bienestar general o en el respeto de los derechos y libertades de los demás ${ }^{30}$.

Podemos así comprobar como algunos requisitos y argumentos de la teoría del Derecho Natural- tal y como aquí se ha planteado- coinciden con algunos elementos esenciales de las teorías sobre los derechos morales y se pueden ver plasmados con evidente nitidez en los enunciados de la Declaración Universal de Derechos Humanos, en cuanto que estos materializan el consenso general sobre los valores a los que dichos derechos responden y que se constituyen fundamentalmente en torno a la idea de dignidad de la persona, puesto que como se señala en su Preámbulo “... la libertad, la justicia y la paz en el mundo tienen por

${ }^{29}$ Rawls, J.,"El Derecho de Gentes", en De los Derechos Humanos, Trotta, Madrid, 1998, pp. 71 y ss.

${ }^{30}$ Abellán Honrubia,V. "La protección internacional de los Derechos Humanos: métodos internacionales y garantías internas", en AAVV., Pensamiento jurídico y sociedad internacional, op. cit., vol. I, pp. 29 y ss. 
base el reconocimiento de la dignidad intrínseca y de los derechos iguales e inalienables de todos los miembros de la familia humana".

Por tanto, creo que las formulaciones de la Declaración- como universalización de los derechos humanos y plasmación de los valores esenciales de la comunidad internacionalaparte de responder en lo sustancial a los planteamientos de esta fundamentación iusnaturalista de carácter histórico y abierto de la que venimos hablando, podrían representar un valioso punto de conexión -superador de muchos prejuicios y malentendidosentre las teorías iusnaturalistas y las teorías de los derechos morales, que funcionan, a su vez, junto con las teorías contractualistas, constructivistas y consecuencialistas.

\section{CONCRECIÓN Y ARTICULACIÓN DE LA PROPUESTA IUSNATURALISTA APLICADA DE LA DECLARACIÓN UNIVERSAL}

Se trataría, por consiguiente, en palabras de I. Berlin de una especie de retorno a la idea antigua del Derecho Natural (no en balde se habla entre los filósofos del Derecho del "eterno retorno del Derecho Natural) "pero para algunos de nosotros con un ropaje empírico, no ya solamente basado en fundamentos teológicos o metafísicos... (porque) hablar de nuestros valores como objetivos universales no equivale a decir que exista algún código objetivo que se nos ha impuesto desde fuera que no podamos quebrantar porque no lo hicimos nosotros; equivale a decir que no podemos evitar aceptar esos principios básicos porque somos humanos. ${ }^{31}$.En un sentido similar, ya desde el ámbito propio y específico de la Filosofía del Derecho, se pronunciaba G..Fasso, cuando decía que, "solo desligado de la idea de un derecho natural metafísico, extra histórico, eterno e inmutable el iusnaturalismo puede encontrar un lugar en la cultura jurídico política actual"32.

Como nuevo Derecho Natural de la Humanidad- entendiendo que las aportaciones de la argumentación iusnaturalista, en los términos expresados, podría todavía resultar altamente idónea para afrontar el problema de la relación entre justicia y Derecho- pienso que la Declaración Universal estaría llamada a desempeñar, básicamente, estas tres funciones en la cultura jurídico-política contemporánea, que, se corresponden, a su vez, con tres de las principales dimensiones en que se manifiesta el valor y alcance de planteamiento iusnaturalista en torno a la reflexión sobre el derecho justo ${ }^{33}$.

$1^{\circ}$ ): La función de legitimación y valoración crítica del orden político y social y de los ordenamientos jurídico- positivos (dimensión crítico-valorativa).Hoy día se afirma sin ambages la necesidad de que los Estados reconozcan y garanticen los derechos humanos. Es más, la legitimación del poder político de un Estado radica, entre otras cosas, en el

${ }^{31}$ Berlin, I. Isahia Berlin en diálogo con Ramin Jahanbegloo, Anaya\&Muchnick Madrid, 1993, pp. 192 y 193.

${ }^{32}$ Fasso, G., "Iusnaturalismo", en Diccionario de Política, N. Bobbio y Matteucci(dirs), vol. I. Siglo XXI, Madrid 1982 p.872.

${ }^{33}$ He suscitado la pauta de esta propuesta-que ahora desarrollo- en algunos trabajos anteriores. Vid.,al respecto Marín Castán, M.L: "La Declaración Universal de Derechos humanos de 10 de diciembre de 1948:¿nuevo Derecho Natural de la Humanidad?”, en La Declaración Universal de Derechos Humanos en su 50 aniversario, M. Balado y J: A. Regueiro(coords), Bosch, Barcelona, 1998, pp y "Declaración Universal de Derechos Humanos y dimensión axiológica de la Constitución “, en Estudios de Teoría del estado y Derecho constitucional en honor de Pablo Lucas Verdú, R. Morodo y P. de Vega(dirs), UNAMFDUCM,Madrid, 2001, Vol III, pp. 1725 y ss. 
reconocimiento y garantía de dichos derechos. Es indudable que la Declaración constituye, en este aspecto, un canon o patrón de valoración que sirve para medir la legitimidad que ostenta el poder de los Estados. Se muestra, en consecuencia, como uno de los parámetros fundamentales en cuya virtud la comunidad internacional puede negar legitimidad a determinados entes estatales; es decir, actúa como un potencial legitimador de todo Estado de Derecho y de su respectiva arquitectura institucional, puesto que representa el "núcleo duro " de los derechos humanos, creando un marco estricto que debe ser cumplido normativamente por todos los ordenamientos internos. Constituye, por tanto, un innegable referente en el reconocimiento jurídico- constitucional de los derechos fundamentales, y como tal, ofrece también la pauta valorativa que fundamenta la disconformidad con determinadas parcelas o amplios sectores de los órdenes jurídicos positivos, así como con las instituciones político- sociales vigentes en cada realidad estatal. La Declaración crea una conciencia jurídica universal de la que ningún Estado quiere sustraerse ${ }^{34}$.

$2^{\circ}$ ) La función de mantenimiento de la esperanza abierta y orientación de futuro hacia una sociedad más justa y hacía un derechojusto (dimensión utópica) ${ }^{35}$. A los enunciados de la Declaración debe reconocérseles una innegable intención utópica, toda vez que estos no representan más que el umbral de una sociedad justa. En virtud de esta dimensión utópica las propuestas de los derechos humanos aparecen habilitadas para encarnar una esperanza universal, si tenemos en cuenta que el caudal utópico- revolucionario ha impregnado siempre el discurso de los derechos humanos, en cuanto realización iniciada y con las expectativas de lo todavía no logrado. E. Bloch, desde su concepción marxista y crítico-radical del iusnaturalismo, considera la lucha por la dignidad humana y la vindicación de los derechos fundamentales, como la herencia constitutiva del Derecho Natural, en su personal versión de éste, como depositario de algunas de las más hermosas aspiraciones de la Humanidad, cual es la búsqueda de la sociedad mejor ${ }^{36}$.Para este autor "pocas cosas hay que hayan sido tan anticipadoramente humanas en razón de sus postulados como el contenido de los derechos del hombre". ${ }^{37}$ Esta característica del Derecho Natural como "horizonte utópico de crítica del derecho positivo"-en gran medida herencia de Bloch-constituye, sin duda, una de las señas de identidad más significativas del iusnaturalismo actual. La dignidad de la persona y los derechos que de ella dimanan son elementos en constante dinamismo y abiertos a ampliaciones, innovaciones y desarrollos futuros. La Declaración no es una propuesta cerrada, definitiva y conclusa: el componente utópico de los derechos humanos es un elemento consustancial a la conceptualización de los mismos y es el que, precisamente, confiere a estos su virtualidad de transformación y actualización.

$3^{\circ}{ }^{\circ}$ ) La función de afirmación del valor de la persona humana y de su protección como fundamento de todo orden jurídico político (dimensión antropológica). En los derechos

${ }^{34}$ Arnold, R. "La Declaración Universal de Derechos Humanos y su importancia para el desarrollo de la cultura del Derecho", en La Declaración Universal...op.cit. pp 59-67

${ }^{35}$ Sobre esta cuestión vid mi trabajo "Sobre el discurso utópico de los derechos humanos. A propósito de dos conmemoraciones: 1948 y 1968”, en Persona y Derecho, Vol 59, (2008), pp.321 y ss

${ }^{36}$ Bloch, E. Derecho Natural y dignidad humana, Aguilar, Madrid, 1980, p. 191; Un interesante trabajo sobre el tema del Derecho Natural en la obra de este autor, puede verse en Serra, F. Historia, Política y Derecho en Ernst Bloch, Trotta, Madrid, 1998, pp141 y ss

37 Ibidem, p. 177 
humanos el hombre se reconoce a sí mismo y se ve impulsado más allá de sí mismo. Los necesita para plantear su propia humanidad y para exigirla. Y la suya sólo puede ser, a la vez, la de todos los otros: la humanidad ${ }^{38}$.La Declaración supone un avance en la tendencia que marca la prioridad del hombre sobre el poder estatal, como seña de identidad del nuevo orden internacionaly, en general, de la cultura jurídica contemporánea, ${ }^{39}$.Es evidente que el eje axiológico en torno al cual gira todo el articulado de la Declaración son las ideas de dignidad, libertad, igualdad y justicia. Desde este plexo axiológico la dignidad humana se constituye como valor material central y fundamento de todos los derechos, configurándose como una especie de "prius" lógico y ontológico de los mismos. Se puede afirmar que con la Declaración Universal la dignidad adquiere un perfil, una orientación y un contenido nuevo, que va a proyectarse en los textos internacionales posteriores de derechos humanos. Así lo pone de relieve el enunciado de apertura de la Declaración, cuando afirma que "todos los seres humanos nacen libres e iguales en dignidad y derechos...”. De ello se deduce la afirmación de la supremacía de la persona y la funcionalización de los órdenes políticos y sociales al servicio de esta visión humanista que sanciona el principio personalista como eje vital de funcionamiento de las instituciones políticas y jurídicas.

\section{ALGUNAS REFLEXIONES FINALES}

Los aniversarios incitan siempre a la reflexión y al análisis. Es preciso reconsiderar, setenta años después de su proclamación, la vigencia y actualidad de la Declaración Universal, así como las perspectivas y proyecciones necesarias en el futuro. Ciertamente, a partir del sucinto texto de dicho documento se iniciaría un proceso, aparentemente imparable, de desarrollo de los derechos humanos a nivel internacional, europeo y estatal. Ahora bien, una cosa es el reconocimiento y la proclamación solemne de los mismos y otra, muy distinta, es la implementación y articulación de mecanismos internacionales garantizadores de su tutela efectiva.

Lograr "todos los derechos humanos para todos", fue el lema elegido por la ONU para conmemorar el cincuentenario de la Declaración Universal. Han pasado veinte años desde entonces y ahora, como entonces, se trata de seguir buscando las formas necesarias para hacer real y efectiva la dignidad de la persona, como fundamento último de la Declaración, puesto que la protección de los derechos humanos básicos que esta consagra sigue siendo bastante precaria y deficiente. Esto es así a pesar de lo logros y avances producidos, a partir de la creación de mecanismos e instituciones para dotar de eficacia a tales derechos, tales como los respectivos Pactos Internacionales de Derechos Civiles y Políticos y de Derechos Económicos, Sociales y Culturales- que son tratados internacionales y vinculan a las partes contratantes-, así como instituciones más recientes, como el Alto Comisionado de las Naciones Unidas para los Derechos Humanos, el Tribunal Penal Internacional (de carácter permanente), el Consejo de Derechos Humanos de Naciones Unidas, las Comisiones de Investigación, las misiones de determinación de los hechos o los Procedimientos Especiales de derechos humanos. Por una parte, resultará necesario reforzar el compromiso interna-

\footnotetext{
${ }^{38}$ Martínez García, J.I."Reconocimiento constitutivo de los derechos humanos", en AAVV Derechos Humanos: Problemas actuales..., op.cit. p.90

39 Arnold, R."La Declaración Universal de Derechos Humanos ..op.cit.p.66
} 
cional de los Estados, mediante la aceptación de los instrumentos existentes y su sometimiento a las instancias de control que revisten carácter facultativo. Por otro lado, es indispensable hacer uniforme el alcance de los compromisos entre las distintas partes contratantes, instando a los Estados a que retiren las reservas formuladas a los distintos instrumentos(como, por ejemplo la negativa de las grandes potencias a ratificar el Estatuto del Tribunal Penal Internacional).Es necesario, a tal fin, promover una mayor cooperación internacional, involucrando a todas las fuerzas operativas y creando un acuerdo vinculante de cooperación global en la defensa de los derechos, a todos los niveles, universal, regional y local ${ }^{40}$ ).En un mundo globalizado deben crearse instrumentos jurídicos globalizadores, más allá de los que conocemos en la actualidad ${ }^{41}$.

El contraste que contemplamos entre el bienestar de unas sociedades y la miseria de otras no se compatibiliza bien con ese ideal moral de la Humanidad en que consiste la Declaración Universal. al igual que tampoco resulta compatible con las guerras y conflictos armados, los genocidios, las migraciones masivas e incontroladas de los últimos tiempos, el hambre de gran parte de la población mundial- que sigue causando estragos- o el fenómeno del terrorismo que asume actualmente dimensiones inéditas. Por otro lado, la universalización de los derechos humanos proclamados por la Declaración no será real y efectiva mientras millones de seres humanos en el mundo desconozcan sus derechos y, en consecuencia, no puedan hacerlos valer frente al poder.

Ahora bien, ello no resta fuerza moral a este significativo documento. Es cierto que es impreciso, que se le ha calificado de etno céntrico- por referir la noción de dignidad a la concepción occidental de dicho valor ${ }^{42}$ y que, en algunos aspectos, ha quedado anticuado, pero hay que analizar las cuestiones con perspectiva histórica y, desde tal punto de vista, debe señalarse que la Declaración representa solo el núcleo mínimo y restringido de la conciencia histórica que la humanidad tenía de sus propios valores y principios fundamentales en la segunda mitad del siglo XX. De tal modo, que los derechos enunciados en ella no son los únicos posibles derechos humanos, son solo los derechos del hombre histórico. Dicho texto fue solo el comienzo de un largo proceso de positivación y supra nacionalización de tales derechos que resultaba entonces absolutamente necesario; no olvidemos que se proclamaba a sí misma como "ideal común por el que todos los pueblos y naciones deben esforzarse".

En el plano de la fundamentación, que es el que aquí interesa, si bien es cierto que la Declaración supuso un avance indiscutible en la conciencia ética mundial, no lo es menos que queda todavía mucho por hacer en la tarea de fundamentar los ordenamientos internos y los instrumentos internacionales en valores éticos compartidos. Parece admitido casi de manera unánime que "los derechos humanos son, en la actual etapa histórica, el código básico de una ética universal aceptable: la ética del respeto a la dignidad personal de los hombres". ${ }^{43}$ En este sentido resultan muy elocuentes y significativas las palabras de K. Apel, quien propugna una ética planetaria de la corresponsabilidad, considerando al respecto, que" es posible salvaguardar el pluralismo de las formas de vida social, solo si se

${ }^{40}$ Castro- Rial, F."La Declaración Universal como elemento básico del orden internacional”, en $L a$ Declaración..op.cit. p.97

${ }^{41}$ Linde Paniagua,,E "La expansión de los derechos humanos", en Derechos Humanos .... op.cit, p.121.

${ }^{42}$ Griffin, J. On Human Rights, Oxford University Press, Oxford, 2008, pp 135-137

${ }^{43}$ Castro Cid, B. Manual de Teoría del Derecho, Ed Universitaria, Madrid, 2007, p.322 
respeta una ética universal de iguales derechos e igual responsabilidad en la solución de los problemas comunes a toda la humanidad" 44 .

Para concluir, creo que las propuestas metodológicas de este Derecho Natural abierto, flexible renovado, progresista y crítico que sugiero, aplicadas al análisis de los enunciados de la Declaración Universal, pueden resultar válidas en la actualidad y suministrar todavía, como hace setenta años, óptimos y fructíferos elementos para la construcción de una ética universal y planetaria tan necesaria en nuestros días y, de la cual dicha Declaración constituyó la primera y más tangible plasmación.

\section{BIBLIOGRAFÍA CONSULTADA}

AA VV. Los derechos humanos. Significación. Estatuto jurídico y sistema, Universidad de Sevilla, Sevilla, 1979.

AA VV Derechos humanos y constitucionalismo ante el tercer milenio, coord. A.E, Pérez Luño, Marcial Pons, Madrid, 1996.

AAVV Consolidación de derechos y garantías: los grandes retos de los derechos humanos en el siglo XXI, CGPJ,, Madrid, 1999.

AAVV Derechos Humanos: Problemas actuales. Estudios en homenaje al Profesor Benito de Castro Cid, coords, N. Martínez Morán, A.M. Marcos del Cano, R. Junquera de Estefaní, UNED,, Madrid, 2013.

AA.VV., Pensamiento jurídico y Sociedad internacional. (Estudios en honor del profesor Truyol Serra) CEC-UCM, Madrid, 1986.

AAVV, La Declaración Universal de Derechos Humanos en su 50 aniversario, coords M. Balado y J. A. Regueiro, Bosch, Barcelona, 1998.

APEL, K.O.”Das problema einer universalistichen Makroethic de Mitverantwortung”, en Deutsche Zeitschrift Philosophie, ${ }^{\circ}$ 2, vol 41(1993).

BALLESTEROS, J. (ed). Derechos Humanos, Tecnos, Madrid, 1992.

BARRANCO AVILÉS, M.C. El discurso de los derechos. Del problema terminológico al debate conceptual. Instituto de Derechos Humanos Bartolomé de las Casas, Universidad Carlos III, Dykinson, Madrid, 1996.

BERLIN, I. Isahia Berlin en diálogo con Ramin Jahanbegloo, Anaya\&Muchnick Madrid, 1993.

BOBBIO, N."Presente y porvenir de los Derechos Humanos" en El tiempo de los derechos, Sistema, Madrid, 1990, LOCH, E. Derecho Natural y dignidad humana, Aguilar, Madrid, 1980.

CARRILLO SALCEDO, J.A. Dignidad frente a barbarie. La Declaración Universal de Derechos Humanos cincuenta años después, Trotta, Madrid, 1999.

CASSESE, A., Los derechos humanos en el mundo contemporáneo, Ariel, Barcelona, 1991.

CASSIN, R. "La Déclaration Universelle et la mise en ouvre des Droits de l"Homme", en Recueil des Cours, $\mathrm{n}^{\circ} 79,1951$, II, pp.239 y ss.

CASTRO CID, B. Manual de Teoría del Derecho, Ed Universitaria, Madrid, 2007.

DELGADO PINTO, J. De nuevo sobre el problema del derecho natural, Universidad de Salamanca, Salamanca 1982.

DIAZ; E.. Sociología y filosofía del derecho, Taurus, Madrid, 1977.

ELLSCHEID, G., "El problema del Derecho Natural. Una orientación sistemática", en Kaufman, A. y Hassemer W. (eds.). El pensamiento jurídico contemporáneo, ed.española de G, Robles, Debate, Madrid 1992, pp145 y ss.

FASSO, G., "Iusnaturalismo", en Diccionario de Política, N. Bobbio y Matteucc (dirs), vol. I. Siglo XXI, Madrid 1982.

FERNÁNDEZ, E. "El iusnaturalismo", en El derecho y la justicia eds. E. Garzón Valdés y F. Laporta, Trotta, C.S.I.C-. B.O.E.:, Madrid, 1996, pp. 55 a 64.

GRIFFIN, J. On Human Rights, Oxford University Press, New York, 2008.

HERNÁNDEZ GIL A. De nuevo y sobre el Derecho Natural, Real Academia de Jurisprudencia y Legislación, Madrid, 1983.

${ }^{44}$ Apel, K.O."Das problema einer universalistichen Makroethic de Mitverantwortung", en Deutsche Zeitschrift Philosophie, $\mathrm{n}^{\circ}$ 2, vol 41(1993), p. 201 
MARÍN CASTÁN, M.L."Declaración Universal de Derechos Humanos y dimensión axiológica de la Constitución ", en Estudios de Teoría del estado y Derecho constitucional en honor de Pablo Lucas Verdú, (dirs) R. Morodo y P. de Vega, UNAM-FDUCM,, Madrid, 2001, Vol III, pp. 1725 y ss.; "Sobre el discurso utópico de los derechos humanos. A propósito de dos conmemoraciones: 1948 y 1968", en Persona y Derecho, Vol 59, (2008), pp.321 y ss.

MEYERS, D. T. Los derechos inalienables, Alianza Universidad, Madrid, 1988.

MUGUERZA, J. y otros, El fundamento de los derechos humanos., Debate, Madrid, 1989.

NINO, C.S. Ética y Derechos Humanos. Un ensayo de fundamentación, Ariel, Barcelona, 1989.

OlLERO TASSARA, A. Derechos humanos y Metodología Jurídica C. E. C., Madrid 1989.

PECES- BARBA, G., Curso de Derechos Fundamentales, (cols). R. de Asís y A. Llamas, Eudema, Madrid, 1991.

PÉREZ LUÑO, A. E. Derechos humanos, Estado de Derecho y Constitución, Tecnos, Madrid, 1984.

RABOSSi, E. "El fenómeno de los derechos humanos, en Revista del Centro de Estudios Constitucionales, $n^{\circ} 3$ (1989).

ROBLES MORCHÓN G, Los derechos fundamentales y la ética en la sociedad actual, Cívitas, Madrid, 1992.

REVENGA, M y CUENCA, P (eds )EL tiempo de los derechos. Los derechos humanos en el siglo XXI, Dykinson, Madrid, 2015.

RAWLS, J. EL Derecho de Gentes y una revisión crítica de la idea de razón pública, Paidós, Barcelona, 2001.

SHUTE, S. y HURLEY, S (eds). De los Derechos Humanos, Trotta, Madrid, 1998.

WELZEL, H. Introducción a la filosofía del derecho. Derecho natural y Justicia material, trad F. González Vicén, Aguilar, Madrid, 1971.

Fecha de recepción: 17 octubre 2018.

Fecha de aceptación: 11 noviembre 2018. 